\title{
EMERGÊNCIA NA SAÚDE PÚBLICA: OS REFLEXOS JURÍDICOS DA CRISE DO CORONAVÍRUS NO ÂMBITO TRABALHISTA E PREVIDENCIÁRIO
}

EMERGENCY IN PUBLIC HEALTH: THE LEGAL REFLECTIONS OF THE CORONAVIRUS CRISIS IN THE LABOR AND SOCIAL SECURITY SCOPE

DOI: http://dx.doi.org/10.16891/2317-434X.v8.e3.a2020.pp649-656

Recebido em: 31.07.2020 | Aceito em: 27.10.2020

Isabele Fernandes Alves da Silva

Centro Universitário Doutor Leão Sampaio - UNILEÃO

*E-mail: isabelefernandes198@gmail.com

\section{RESUMO}

A recente crise causada pelo novo agente do Coronavírus, Covid-19 - doença respiratória descoberta e registrada em dezembro de 2019, influenciou inúmeros ordenamentos jurídicos a adotarem medidas de enfrentamento à insegurança jurídica causada, especialmente nos âmbitos previdenciário e trabalhista. Em 30 de janeiro de 2020 , a Organização Mundial da Saúde (OMS) declarou a situação de Emergência de Saúde Pública de Importância Internacional em decorrência do novo Coronavírus. No Brasil, a Portaria $n^{\circ} 188$, do Ministério da Saúde, bem como o primeiro projeto de lei que foi encaminhado pelo Presidente da República ao Congresso Nacional, em 04 de fevereiro de 2020, declararam e regulamentaram a emergência na saúde pública, sendo o primeiro caso de coronavírus registrado, em território nacional, em 26 de fevereiro de 2020. Na seara trabalhista e previdenciária, a Lei 13.979, de 06 de fevereiro de 2020, trouxe algumas medidas que afetaram as relações jurídicas estabelecidas, tendo sido a Medida Provisória n. 922, de 28 de fevereiro de 2020, o primeiro ato que dispôs acerca dessas questões, trazendo regras de contratação temporária no serviço público. Desde então, a União enfrenta um desafio em relação à elaboração de normas eficientes para driblar a atual crise econômica agravada, tendo em vista que a economia brasileira já vinha dando suspiros desde 2014. Sendo assim, as novas relações jurídicas, na seara previdenciária e trabalhista, estabelecidas, nesse período excepcional, serão exploradas, de maneira extensiva, no presente estudo.

Palavras-chave: Coronavírus; Insegurança jurídica; Relações trabalhistas.

\section{ABSTRACT}

The recent crisis caused by the new Coronavirus agent, Covid-19 - a respiratory disease discovered and recorded in December 2019, has influenced numerous legal systems to adopt measures to address the legal insecurity caused, especially in the social security and labor spheres. On January 30, 2020, the World Health Organization (WHO) declared the Public Health Emergency situation of International Importance due to the new Coronavirus. In Brazil, Decree number 188, of the Minister of Health, as well as the first bill that was sent by the President of the Republic to the National Congress, on February 4, 2020, declared and regulated the emergency in public health, being the first case of coronavirus registered, in national territory, on February 26, 2020. In the labor and social security field, Law 13.979, of February 6, 2020, brought some measures that affected the established legal relationship, having been Provisional Measure number 922, of February 28, 2020, the first act that dealt with these issues, bringing temporary hiring rules in the public service. Since then, the Union has faced a challenge in relation to the elaboration of efficient norms to overcome the current aggravated economic crisis, considering that the Brazilian economy has been sighing since 2014. Therefore, the new legal relationships, in the social security and labor field established, in this exceptional period, will be explored, extensively, in the present study.

Keyword: Coronavirus; Juridical insecurity; Labor relations. 


\section{INTRODUÇÃO}

O presente artigo visa analisar a crise, sem precedentes, que a situação excepcional de Pandemia causou, afetando, sobretudo, as relações previdenciárias e trabalhistas. Dentre as questões levantadas nesse período, deve-se observar que a dignidade da pessoa humana, principal princípio que permeia essas relações, bem como alguns direitos e garantias constitucionais do trabalhador foram flexibilizados sem observância constitucional.

Num primeiro momento, observou-se um intenso processo legislativo, sendo a Lei 13.979 , de 06 de fevereiro de 2020, a primeira legislação federal que regulamentou aspectos importantes de enfrentamento do Coronavírus. Ainda observa-se a grande importância da Lei 13.982, de 02 de abril de 2020, que instituiu o auxílio emergencial, como instituto de proteção do trabalhador informal, e outras medidas de interesse social.

Considerando a atribuição de competência do Presidente da República, foram publicadas as Medidas Provisórias de n. 927, 936 e 944, todas com delineamentos previdenciários e trabalhistas e que serão abordadas no estudo. Na seara trabalhista, a grande controvérsia se concentra na figura das associações sindicais, que foram invisibilizadas na contramão de dispositivos constitucionais.

Portanto, ressalta-se que nem todas essas medidas foram recepcionadas de forma positiva por todos os setores sociais, sendo ainda alvos de críticas em relação à sua aplicação, como será abordado, extensivamente, no estudo.

\section{METODOLOGIA}

O método de pesquisa adotado é do tipo exploratório, o qual objetiva uma compreensão e esclarecimento extensivo do objeto escolhido para estudo. Sendo assim, deve-se ressaltar que "as pesquisas exploratórias constituem a primeira etapa de uma pesquisa mais ampla. Afinal, quando o assunto abordado é bastante genérico, é necessário fazer delimitações e outros tipos de procedimentos"'. (LOZADA; NUNES, 2018).

O presente estudo compreende uma análise precípua da legislação trabalhista, tendo esta sofrido consideráveis alterações desde que se constatou a situação de emergência causada pela pandemia, a qual produziu efeitos na sociedade e, consequentemente, no ordenamento jurídico.

Além disso, optou-se por uma análise indutiva, levando em consideração que a efetivação da pesquisa se deu a partir da observância de fatos particulares resultando em um desenlace geral.

\section{RESULTADOS E DISCUSSÃO OBSERVÂNCIA CONSTITUCIONAL LEGISLAÇÃO TRABALHISTA EXCEPCIONAL}

A Lei 13.979/20 trouxe a definição legal do termo 'quarentena', sendo que o descumprimento desta e de outras medidas previstas na lei poderão gerar responsabilização, inclusive a demissão por justa causa, tendo sido estabelecido, inicialmente, o prazo de 14 dias de quarentena, possível de ser estendido por igual período.

Em primeiro plano, ressalta-se que os planos de benefícios da previdência social estão dispostos no art. 60, $\S 3^{\circ}$, da lei $\mathrm{n}^{\circ} 8.213$, de 1991 , onde é abordado que havendo afastamento do empregado por motivos de doença é dever da empresa pagar a devida remuneração do mesmo nos primeiros 15 dias consecutivos. Decorrido esse prazo legal e não havendo o retorno do empregado pelo mesmo motivo, é dever do Estado, por meio do Instituto Nacional do Seguro Social - INSS, garantir o pagamento do valor devido de auxílio-doença, de acordo com a previsão do art. 59, da Lei 8.213/91. A percepção desse benefício será legitimada em havendo inaptidão do empregado para o trabalho.

Havendo a conexão entre os dois dispositivos legais, percebe-se que o salário integral a ser pago pela empresa compreenderá ao prazo de 14 dias de reclusão estabelecido.

Entretanto, surgiram divergências acerca da responsabilização da garantia de recebimento de salário ou do benefício de auxílio-doença, já que direitos precisariam ser assegurados, mas a problemática concentrava-se em quem os asseguraria.

Mas antes de adentrar em tal discussão, é importante destacar que o salário é um direito do trabalhador consolidado constitucionalmente. Portanto, diante de controvérsias acerca da sua garantia é dever do Estado promover à sua efetivação, de acordo com Rogério Renzetti:

Em regra, o trabalhador tem direito a receber o seu salário de forma integral, sem sofrer qualquer desconto abusivo [...]. Não podemos afastar a natureza alimentar do salário, que faz com que o empregado garanta a sua subsistência e a de sua família, não podendo haver restrição à disposição do seu salário. (RENZETTI, Rogério, 2018, GRIFO NOSSO).

A Lei 13.982, de 02 de abril de 2020, trouxe uma aparente pacificação dessa questão, já que previu a possibilidade de esses primeiros 15 dias, que compreendem o período de reclusão do empregado decorrente de sua contaminação pelo coronavírus, serem 
deduzidos do repasse da previdência patronal. Mas, as contínuas divergências foram suficientes para a elaboração de um Projeto de Lei que prevê a hipótese de o governo arcar com o pagamento do salário integral correspondente aos primeiros 15 dias. Além disso, foi apresentado o Projeto de Lei n. 2.126, estabelecendo que em decorrência da situação de isolamento o empregado será dispensado de apresentar comprovação de atestado médico, no período de 7 dias.

O cumprimento desses requisitos, cumulados com medidas a serem adotadas pelo Estado e por empresas, que proporcionem aos empregados meios adequados de enfrentamento ao Coronavírus, asseguram direitos sociais ao trabalhador, garantidos no art. $7^{\circ}$, da Constituição Federal.

Objetivando contornar os efeitos da crise, a Lei 13.982/20 regulamentou medidas de proteção social, como o Benefício de Proteção Social (BPC), que já era previsto como garantia da pessoa idosa, da pessoa com deficiência ou de outros indivíduos que se encontrem em condição de vulnerabilidade social na lei 8.742/1993; e o auxílio emergencial, no valor de $\mathrm{R} \$ 600,00$ ou o dobro desse valor em se tratando de mulher que sustenta a família sozinha, visando amparar o trabalhador informal, seja empregado, autônomo ou desempregado; o contribuinte individual da Previdência Social; e o microempreendedor individual.

Como mencionado, as medidas protetivas da lei 13.979/20 visam amparar o empregado e empregador, proporcionando estabilidade às relações previdenciárias e trabalhistas, pois a interrupção, por parte da empresa, nos primeiros 15 dias e a suspensão do contrato de trabalho, por parte do Estado, a partir do $16^{\circ}$ dia, asseguram uma continuidade na relação de emprego e efetivação de direitos sociais do empregado. Sendo assim, observa-se a importância da responsabilização dos dois entes mencionados às novas circunstâncias emergidas, tendo estes papéis importantes na prevenção da precarização das relações trabalhistas. Já a Lei 13.982/20 trouxe medidas concretas de amparo às condições de vulnerabilidade do trabalhador. Desse modo, observa-se que, apesar das divergências enfrentadas, as leis objetivam assegurarar o mínimo ético, nos moldes da dignidade da pessoa humana.

\section{OBSERVÂNCIA DOS DIREITOS SOCIAIS NAS MEDIDAS PROVISÓRIAS EMERGENCIAIS}

De acordo com o art. 62, caput, da Constituição Federal, o Presidente da República poderá adotar Medida Provisória para legislar sobre assunto de relevância e urgência, devendo a mesma ser submetida ao Congresso Nacional. Conforme bem explanado por Guilherme Peña de Moraes (2019), a medida provisória perderá sua eficácia se não for convertida em lei no prazo de 60 dias.
Tendo em vista a situação de relevância e urgência ocasionadas pela crise do Coronavírus, são de extrema relevância, para o âmbito trabalhista, as Medidas Provisórias de números 927, 936 e 944, sendo a seguir abordados os seus principais requisitos.

\section{MEDIDA PROVISÓRIA DE $\mathbf{N}^{\circ} 927 \quad \mathrm{E} \quad$ O DESCOMPASSO COM A CONSTITUIÇÃO FEDERAL}

A Medida Provisória de $\mathrm{n}^{\circ}$ 927, publicada em 22 de março de 2020, trouxe importantes medidas de enfrentamento aos efeitos econômicos, decorrentes do estado de calamidade pública, dentre as medidas abordadas foram escolhidas para compor o presente estudo: o teletrabalho; a antecipação de férias individuais; a concessão de férias coletivas; o banco de horas e a suspensão de exigências administrativas em segurança e saúde no trabalho.

O teletrabalho é caracterizado pela prestação de serviços preponderantemente ou totalmente fora das dependências do empregador, por meio da utilização de tecnologias de informação e comunicação. A referida Medida Provisória em seu art. $4^{\circ}$, trouxe a possibilidade de o empregador alterar o regime de trabalho presencial para o teletrabalho, trabalho remoto ou outro tipo de trabalho à distância, devendo a alteração ser notificada ao empregado com antecedência mínima de 48 horas.

Todavia, mesmo havendo o Princípio da Alteridade no Direito do Trabalho, que afirma que os riscos da atividade econômica devem ser suportados pelo empregador, no Brasil, é praticamente inviável a prestação de serviços por meio do teletrabalho, considerando que muitos trabalhadores não têm acesso à internet ou se possuem, o acesso é precário. Então, medidas não devem ser elaboradas apenas observando o sentido formal, devese observar a sua efetivação prática.

A antecipação de férias individuais e a concessão de férias coletivas serão oferecidas a critério do empregador, com antecedência mínima de 48 horas. Além disso, o empregador está dispensado da comunicação prévia ao órgão local do Ministério da Economia e sindicatos, tratada no art. 139, da CLT, o que contribui com uma marginalização da figura das entidades sindicais, que possuem relevância constitucional na efetivação de direitos sociais do trabalhador.

No caso da interrupção das atividades pelo empregador, será estabelecida compensação das horas excedentes trabalhadas, mediante acordo individual ou coletivo, através do instituto conhecido como banco de horas. A compensação das horas terá o seu prazo de doze meses, previsto no art. $58, \S 2^{\circ}$, da CLT, ampliado para até dezoito meses, contado a partir da data de encerramento da situação de calamidade pública, que dura até 31 de 
dezembro de 2020, conforme disposto pelo Decreto Legislativo $\mathrm{n}^{\circ}$ 06, de 2020. A compensação de tempo deverá respeitar o limite de duas horas diárias além do período da jornada comum, não excedendo as dez horas diárias, e a mesma não dependerá de convenção coletiva ou acordo individual ou coletivo. Nesse caso, percebe-se, novamente, que houve a invisibilização da figura do sindicato nas relações laborais.

Nas relações trabalhistas, a principal atribuição das entidades sindicais é defender interesses direitos coletivos ou individuais, inclusive, através das negociações coletivas. Assim, o sindicato é o intermediário na relação estabelecida entre empregado e empregador, tratando-se de um importante integrante na elaboração de normas a serem aplicadas nos contratos de trabalhos individuais, conforme assegura a Convenção n. 98 da Organização Internacional do Trabalho:

Deverão ser tomadas, se necessário for, medidas apropriadas às condições nacionais, para fomentar e promover o pleno desenvolvimento e utilização dos meios de negociação voluntária entre empregadores ou organizações de empregadores e organizações de trabalhadores com o objetivo de regular, por meio de convenções, os termos e condições de emprego. (GRIFO NOSSO, CONVENÇÃO N. 98 DA ORGANIZAÇÃO INTERNACIONAL DO TRABALHO, art. $4^{\circ}$, 1953).

Além disso, é importante a menção de um trecho da nota à imprensa divulgada pelo Ministério Público do Trabalho:

[...] O Ministério Público do Trabalho também reforça o seu entendimento de que o diálogo social pode conduzir a medidas mais acertadas e, principalmente, que envolvam as classes trabalhistas e empresarial. Por essa razão, também vê com preocupação a não participação das entidades sindicais na concepção de medidas e a permissão de que medidas gravosas sejam feitas sem a sua participação.

Diante do exposto, vê-se que a MP 927, viola o que é estabelecido na Constituição Federal, bem como na Convenção n. 98 da Organização Internacional do Trabalho, ao estabelecer a supremacia de acordos individuais em detrimento de negociações coletivas, deixando a critério do empregador a tomada de importantes decisões de maneira unilateral, o que contribui com um enfraquecimento das relações trabalhistas.

A última medida abordada no presente estudo e trazida pela MP 927, foi a suspensão da realização dos exames médicos ocupacionais, clínicos e complementares, com exceção dos exames demissionais. Essas exigências deverão ser realizadas no período de sessenta dias, após a data de encerramento do estado de calamidade pública. Além disso, será suspensa a obrigatoriedade de realização de treinamentos periódicos e eventuais dos atuais empregados, os quais serão realizados no prazo de noventa dias, contado da data de encerramento do estado de calamidade pública. Essa medida também comprometeu garantias fundamentais determinadas pela Constituição Federal, como a saúde e bem-estar social do empregador.

Diante das controvérsias geradas, a referida medida provisória não foi convertida em lei e, portanto, caducou no dia 19 de julho de 2020, considerando, ainda, as divergências de acordo entre o Governo Federal e o Congresso Nacional.

\section{MEDIDA PROVISÓRIA DE $\mathbf{N}^{\circ} \quad 936$ E A INVISIBILIZAÇÃO DAS ENTIDADES SINDICAIS}

A Medida Provisória de $n^{\circ} 936$, publicada em $1^{\circ}$ de abril, a qual foi convertida na Lei 14.020/20, instituiu, o Programa Emergencial de Manutenção do Emprego e da Renda que teve como principal objetivo minimizar os impactos sociais gerados pela crise do coronavírus, de modo a preservar o emprego e a renda, além de garantir a continuidade das atividades laborais e empresariais.

Além destes objetivos, essa MP trouxe como medidas do Programa Emergencial de Manutenção do Emprego e da Renda, conforme disciplinado no art. $3^{\circ}$ do referido dispositivo, o pagamento de Benefício Emergencial de Preservação do Emprego e da Renda, a redução proporcional de jornada de trabalho e de salários e a suspensão temporária do contrato de trabalho, as quais objetivam reduzir os impactos econômicos e o desemprego, decorrentes da crise do coronavírus, que afetam, sobretudo, os empregados.

Convém destacar que o Princípio da Irredutibilidade Salarial garante ao empregado o direito de não ter seu salário reduzido, seja na situação de redução direta de salário ou na hipótese de redução de tarefas e consequente redução de salário. De modo geral, convenções ou acordos coletivos podem discutir acerca da redução salarial, conforme disposto no art. $7^{\circ}$, VI, da Constituição Federal. Nessa situação, a redução de salário ocorre em concomitância com a redução de jornada somente quando precedida de negociação coletiva, ou seja, havendo a necessidade de atuação dos sindicatos. Ademais, a CLT deverá observar as regras constitucionais para a redução de salário, de acordo com Carlos Henrique Bezerra Leite:

[...] Pode-se afirmar que o art. 503 da CLT e a Lei 4.923/65 (art. $2^{\circ}$ ), que admitiam a redução do salário por motivos decorrentes de força 
maior e dificuldades econômicas da empresa, respectivamente, devem ser interpretados conforme a Constituição, no sentido de que somente será permitida a redução salarial por meio de convenção ou acordo coletivo e desde que devidamente comprovada pelo menos uma das seguintes situações: força maior e/ou dificuldades econômicas da empresa. (LEITE, 2020, p. 508, GRIFO NOSSO).

A CLT prevê o princípio da irredutibilidade salarial, de forma implícita, em seu art. 468, estabelecendo a licitude da alteração no contrato de trabalho, em havendo consentimento mútuo. Mas, as alterações que acarretam prejuízo ao trabalhador são vedadas pelo próprio artigo, sob pena de nulidade da cláusula que transgrida esse direito.

Na contramão da previsão constitucional, que possibilita a flexibilização da jornada de trabalho e salário, por meio negociação coletiva, à luz do art. $7^{\circ}$, incisos VI, XIII e XIV da Constituição Federal, a MP 936 trouxe a possibilidade de redução proporcional de jornada de trabalho e salário por meio de acordo individual entre empregado e empregador, no período de até 90 dias. Em razão disso, nota-se que as relações trabalhistas advindas com esse novo cenário de calamidade pública, contribuíram com a invisibilização da função do sindicato na representação coletiva, prevista no art. $8^{\circ}$, III, da Constituição Federal.

Por tudo isso, a prevalência de negociações individuais suprimem a função das associações sindicais, que representam uma entidade de proteção do empregado, como parte hipossuficiente, frente às relações com o empregador.

Portanto, $\mathrm{o}$ art. $7^{\circ}$, da Constituição Federal, aborda direitos sociais que não poderão sofrer retrocessos, em razão de se tratarem de direitos fundamentais. Posto isso, percebe-se que a priorização das negociações individuais sobre as negociações coletivas são consideradas inconstitucionais, em razão da flexibilização de direitos trabalhistas que só seriam possíveis por intermédio das associações sindicais.

A Ação Direta de Inconstitucionalidade 6363 ainda questionou essa inobservância da MP 936 com a Constituição Federal. Nessa ADI, o Ministro Relator Ricardo Lewandowski estabeleceu que a validade do acordo individual para redução de jornada em concomitância com a redução do salário, bem como para a suspensão do contrato de trabalho, deveria ser comunicada às entidades sindicais, e em caso de omissão desta, o acordo seria convalidado automaticamente. Essa comunicação teria a finalidade de proteção ao trabalhador. Por outro lado, não houve uma decisão favorável a esse posicionamento, o que tornou o conteúdo do art. $11, \S 4^{\circ}$, da MP 936 um requisito desnecessário à validade dos acordos individuais de redução de jornada de trabalho e de salário e suspensão temporária do contrato de trabalho.

Na MP 936, há a previsão para uma redução de $25 \%, 50 \%$ e até $70 \%$ em se tratando de empregado com diploma de ensino superior e com salário superior ao dobro do teto da previdência $(\mathrm{R} \$ 12.202,12)$ e daqueles que recebem salário equivalente a um valor de até três salários mínimos ( $\mathrm{R} \$ 3.135,00)$, sendo que essa redução poderia se dar através de acordo individual entre empregado e empregador. Na hipótese de redução de até $25 \%$, o acordo poderia ser individual ou coletivo. Para essa redução, a MP estipulou a observância dos seguintes requisitos: manutenção do valor do salário-hora de trabalho; pactuação por acordo individual entre empregado e empregador; e redução da jornada de trabalho e de salário nos percentuais de $25 \%, 50 \%$ ou $70 \%$.

No Direito do Trabalho, a suspensão do contrato de trabalho se dá quando as obrigatoriedades entre empregado e empregador são dispensadas temporariamente, não sendo esse período computado como tempo de serviço. Essa situação pode resultar em não obrigatoriedade do pagamento do salário, por parte do empregador, e da prestação de serviço, por parte do empregado, quando se tratar de suspensão total; ou quando o empregado susta suas atividades, mas continua recebendo seu salário, sendo esta a suspensão parcial. Algumas das hipóteses de suspensão do contrato de trabalho ocorrem nos casos de greve, acidente de trabalho, afastamento do empregado por motivo de doença, entre outras situações.

$\mathrm{Na}$ Medida Provisória $\mathrm{n}^{\circ}$ 936, a suspensão temporária do contrato de trabalho poderá ser pactuada por meio de acordo individual entre empregado e empregador, no prazo de até 60 dias, podendo este ser subdividido em dois períodos iguais. Esse acordo deverá ser encaminhado ao empregado com antecedência mínima de dois dias.

No período de 60 dias, que se refere ao prazo de suspensão do contrato de trabalho, haverá a interrupção da prestação do serviço e do pagamento do salário. A suspensão do contrato de trabalho e, consequente, interrupção do pagamento do salário, possibilitará ao empregado o direito de se valer do benefício do segurodesemprego.

Além da observância da validade do acordo individual entre empregado e empregador prevista na MP 936, a Lei 14.020/20 estabeleceu a prevalência da negociação coletiva se esta conflitar com as condições estipuladas no acordo individual. Ademais, o trabalhador terá garantia provisória no emprego durante o período de acordo de redução de jornada e salário ou suspensão do contrato de trabalho. Havendo, ainda, a garantia de emprego, por proibição de dispensa sem justa causa, do trabalhador deficiente durante o período de calamidade 
pública.

A referida MP foi prorrogada, por meio de decreto, e terá seus efeitos estendidos. Ou seja, a suspensão de contratos e redução de jornada e salários ainda serão possíveis até o final do ano de 2020. Todavia, especialistas ponderam que a prorrogação dessa medida pode afetar o $13^{\circ}$ salário, que constitui um direito garantido constitucionalmente, considerando que este é pago conforme os meses trabalhados e o valor do salário em dezembro. É nesse contexto que também se percebe a importância das negociações coletivas, porque estas devem prevalecer sobre a lei.

Em virtude do exposto, nota-se que nesse período de crise, o que está em jogo não é somente a condição social das pessoas, mas a efetivação de princípios fundamentais, previstos no art. $1^{\circ}$, incisos III e IV, da Constituição Federal, os quais abrangem os direitos sociais dos trabalhadores. É forçoso esclarecer, ainda, que Medidas Provísórias, em sentido contrário à Constituição, não podem ser motivadas por situação de relevância e/ou emergência pública, já que direitos fundamentais não podem ser flexibilizados, senão em detrimento de outros.

\section{MEDIDA PROVISÓRIA DE Nº 944}

A Medida Provisória n. 944, publicada em 3 de abril de 2020, instituiu o Programa Emergencial de Suporte a Empregos, o qual visa auxiliar as empresas com o financiamento da sua folha de pagamento. Esse auxílio, prestado pelo governo e instituições financeiras, deverá ser atribuído às empresas que contratarem as linhas de crédito do Programa Emergencial de Suporte a Empregos, as quais deverão assumir obrigações contratuais, como o fornecimento de informações verídicas, a utilização dos recursos para o pagamento dos empregados e a impossibilidade de rescisão contratual, sem justa causa, dos contratos de trabalho de seus empregados, no período compreendido entre a data da contratação da linha de crédito e 60 dias após o recebimento da última parcela da linha de crédito. A inobservância dessas obrigações resulta em vencimento antecipado da dívida.

O Programa Emergencial citado é destinado às sociedades empresárias e cooperativas (excetuadas as sociedades de crédito), que tiveram, em 2019, lucro superior a $\mathrm{R} \$ 360.000,00$ (trezentos e sessenta mil reais) e igual ou inferior a $\mathrm{R} \$ 10.000 .000,00$ (dez milhões de reais). Essas empresas apenas terão acesso às linhas de crédito do Programa caso tenham sua folha de pagamento processada por instituição financeira participante.

A MP possibilitou que a maior parte da linha de crédito, $85 \%$, fosse concedida por bancos públicos e o restante seria assumido pelo setor privado. Entretanto, observa-se uma falta de efetividade por parte dos bancos privados, mesmo havendo apoio do setor público, atingindo os agentes que seriam beneficiados pelo programa. O resultado dessa ineficiência do setor público em assumir o controle do risco operacional é a previsão de endividamento dos empreendedores, o que fere os valores sociais do trabalho e da livre iniciativa, fundamentos da República Federativa do Brasil, segundo art. $1^{\circ}$, IV da Constituição Federal.

Derivada da MP 944, foi sancionada a Lei 14.043, que instituiu o Programa Emergencial de Suporte a Empregos. Essa lei possibilitou uma ampliação do rol de agentes econômicos beneficiados pela linha de crédito, como pode-se citar as organizações religiosas, além de facilitar o acesso ao crédito e concessão de garantias para microempresas e empresas de pequeno porte.

Apesar das novas alterações advindas com a lei, ainda uma omissão do Estado na elaboração de meios de aporte ao microempreendedor individual e à microempresa, considerando seus faturamentos inferiores a R\$ 360.000,00 . É inegável que ações protetivas para os pequenos negócios seriam necessárias para efetivação de direitos sociais, o que garantiria a subsistência de milhares de trabalhadores que estão sem apoio e, consequentemente, comporão apenas números no índice de desempregados desse período.

\section{CONSIDERAÇÕES FINAIS}

A presente pesquisa teve como objetivo geral o estudo dos impactos do estado de calamidade pública, decorrentes do novo coronavírus, nas relações trabalhistas e previdenciárias, tendo em vista que estas foram alteradas consideravelmente para adaptarem-se à nova realidade social.

Nesse período excepcional, a expectativa para a produção legislativa foi a de uma possível efetivação na segurança jurídica da relação estabelecida entre empregado e empregador. Entretanto, a realidade adversa se tornou uma justificativa para uma produção legislativa que não priorizou alguns ditames da Constituição Federal, como a ausência da figura da entidade sindical nas novas relações estabelecidas, que seria o meio através do qual ocorreria um diálogo social, com fins de proteção aos direitos sociais do trabalhador, e a edição de medidas provisórias que suspendem contratos de trabalho e que reduzem salários.

Assim sendo, apesar das adversidades, o momento exige uma cooperação entre o Estado e a coletividade, bem como entre empregado e empregador, com fins de efetivação dos interesses sociais e respeito, sobretudo, à dignidade da pessoa humana. 


\section{REFERÊNCIAS}

BOLETIM Legislativo Covid-19: Projeto de Lei no 2126, de 2020. Sindigêneros RS, 08 de maio de 2020. Disponível em:<https://www.sgenerosrs.com.br/boletimlegislativo-covid-19-projeto-de-lei-no-2126-de-2020dispensa-o-empregado-de-apresentar-atestado-medico/>. Acesso em: 15 de junho de 2020.

BRASIL. [Constituição (1988)]. Constituição da República Federativa do Brasil. Brasília, DF: Senado, 1988.

BRASIL. Decreto Legislativo ${ }^{\circ}$ 06, de 2020. Disponível em:<http://www.planalto.gov.br/ccivil_03/portaria/DLG6

2020.htm\#: :text=DECRETO $\% 20$ LEGISLATIVO $\% 20 \mathrm{~N}$ $\%$ C2\%BA\%206\%2C\%20DE, 18\%20de\%20mar\%C3\%A 7o\%20de\%202020.>. Acesso em: 18 de junho de 2020.

BRASIL. Lei $n^{\circ}$ 13.979, de 06 de fevereiro de 2020.Disponível em: $<$ http://www.in.gov.br/en/web/dou//lei-n-13.979-de-6-de-fevereiro-de-2020-242078735>. Acesso em: 08 de junho de 2020.

BRASIL. Lei $n^{\circ}$ 13.982, de 02 de abril de 2020.Disponível em:<http://www.in.gov.br/en/web/dou//lei-n-13.982-de-2-de-abril-de-2020-250915958>. Acesso em: 10 de junho de 2020.

BRASIL. Lei $n^{\circ}$ 14.020, de 06 de julho de 2020.Disponível em: $<$ http://www.in.gov.br/en/web/dou//lei-n-14.020-de-6-de-julho-de-2020-265386938>.

Acesso em 15 de julho de 2020.

BRASIL. Medida Provisória ${ }^{\circ}$ 927, de 22 de março de 2020. Dispõe sobre as medidas trabalhistas para enfrentamento do estado de calamidade pública reconhecido pelo Decreto Legislativo $\mathrm{n}^{\circ}$ 6, de 20 de março de 2020, e da emergência de saúde pública de importância internacional decorrente do coronavírus (covid-19), e dá outras providências. Diário Oficial da União, Brasília, DF. Seção 1, p. 1.

BRASIL. Medida Provisória $n^{\circ}$ 936, de 01 de abril de 2020. Institui o Programa Emergencial de Manutenção do Emprego e da Renda e dispõe sobre medidas trabalhistas complementares para enfrentamento do estado de calamidade pública reconhecido pelo Decreto Legislativo $n^{\circ} 6$, de 20 de março de 2020, e da emergência de saúde pública de importância internacional decorrente do coronavírus (covid-19), de que trata aLei $\mathrm{n}^{\circ} 13.979$, de 6 de fevereiro de 2020, e dá outras providências. Diário
Oficial da União, Brasília, DF. Seção 1, p. 1.

BRASIL. Medida Provisória $n^{\circ}$ 944, de 03 de abril de 2020. Institui o Programa Emergencial de Suporte a Empregos. Diário Oficial da União, Brasília, DF. Seção 5, p. 1.

CHIARO, J. D.; CABRAL, M. A. M.; BONETTI, I. J. Os desafios gerados pela pandemia ocasionada pelo Coronavírus e questões jurídicas conexas. 12 de março de $2020 . \quad$ Disponível em: <https://www.migalhas.com.br/depeso/321560/osdesafios-gerados-pela-pandemia-ocasionada-pelocoronavirus-e-questoes-juridicas-conexas>. Acesso em: 18 de junho de 2020 .

COMO funciona o acordo de suspensão ou redução do contrato de trabalho durante a pandemia do Coronavírus? Âmbito Jurídico, 04 de maio de 2020. Disponível em: $<$ https://ambitojuridico.com.br/cadernos/direito-dotrabalho/acordo-suspensao-reducao-contrato-trabalho/>. Acesso em: 02 de julho de 2020.

FOLHA informativa - COVID-19 (doença causada pelo novo coronavírus). OPAS Brasil, atualizado em 29 de julho de 2020 . Disponível em: <https://www.paho.org/bra/index.php?option=com_conte nt $\&$ view $=$ article $\&$ id $=6101:$ covid19\&Itemid $=875>$.

Acesso em: 29 de julho de 2020.

LACERDA, Lara. MP de auxílio à folha de pagamento é alvo de críticas. Brasil de Fato. São Paulo, 08 de julho de 2020.

Disponível em:<https://www.brasildefato.com.br/2020/07/08/mp-deauxilio-a-folha-de-pagamento-e-alvo-de-

criticas\#: : :text=Entre\%20os\%20problemas\%2C\%20est $\% \mathrm{C} 3 \%$ A3o\%20a,e\%20exig\%C3\%AAncia\%20de $\% 20$ fat uramento $\% 20$ alto\&text=Nesta $\% 20$ semana $\% 200 \% 20$ Sen ado\%20deve,honrarem\%20as\%20folhas\%20de\%20paga mento.>. Acesso em 17 de outubro de 2020.

LEITE, Carlos Henrique Bezarra. Curso de direito do trabalho. - 12. ed. - São Paulo: Saraiva Educação, 2020.

LOZADA, Gisele; NUNES, Karina da Silva. Metodologia Científica. Porto Alegre: Sagah, 2018.

MORAES, Guilherme Peña de. Curso de direito constitucional / Guilherme Peña de Moraes. - 11. ed. São Paulo: Atlas, 2019. 
MP prevê novas regras para redução de jornada e salário e suspensão de contrato. Agência Senado, 02 de abril de 2020 . Disponível em:<https://www12.senado.leg.br/noticias/materias/2020 /04/02/mp-preve-novas-regras-para-reducao-de-jornadae-salario-e-suspensao-de-contrato>. Acesso em: $02 \mathrm{de}$ julho de 2020.

NOTA À IMPRENSA: MPT vê com extrema preocupação trechos importantes da MP 927. Democracia e Mundo do Trabalho em debate. 23 de março de 2020. Disponível em:<http://www.dmtemdebate.com.br/nota-aimprensa-mpt-ve-com-extrema-preocupacao-trechosimportantes-da-mp-927/>. Acesso em 15 de outubro de 2020 .

\section{OIT. Organização Internacional do Trabalho.}

Disponível em:

<https://www.ilo.org/brasilia/convencoes/WCMS_23518 8/lang--pt/index.htm>. Acesso em 15 de outubro de 2020.

OLIVEIRA, Maria Teresa Vieira da Silva; GUBERT, Maria Beatriz Vieira da Silva. A MP 927 caducou, e agora?. Revista Consultor Jurídico, 27 de julho de 2020. Disponível em: <https://www.conjur.com.br/2020-jul-27/oliveira-gubertfim-mp-927-

agora\#: :text=A\%20Medida\%20Provis\%C3\%B3ria $\% 20$ 927\%2C\%20de,medida\%20provis\%C3\%B3ria\%20referi da\%20iria\%20caducar.>. Acesso em 16 de outubro de 2020 .

OTSUKA, L. B. L.; TSIFLIDIS, A. C.; OLENIKE, J. G. A conversão da MP 936 na lei 14.020 - O que mudou?. 9 de julho de 2020. Disponível em: <https://www.migalhas.com.br/depeso/330438/aconversao-da-mp-936-na-lei-14020-o-que-

mudou\#: :text=A\%20lei\%2014.020\%2C\%20de\%206,de $\% 20$ suspens $\%$ C3\%A3o\%20de\%20contratos $\% 20 \mathrm{de}>$.
Acesso em: 18 de julho de 2020.

PERDE vigência MP que permitia contratação temporária de servidores aposentados. Agência Senado, 30 de junho de 2020.

Disponível

em:<https://www12.senado.leg.br/noticias/materias/2020 /06/30/perde-vigencia-mp-que-permitia-contratacaotemporaria-de-servidores-aposentados>. Acesso em: 05 de julho de 2020 .

PORTARIA MS n 356 - Medidas de Enfrentamento ao COVID - 19. Anahp, 12 de março de 2020. Disponível em:<https://www.anahp.com.br/noticias/covid-

19/portaria-ms-no-356-de-11-de-marco-de-2020/>. Acesso em: 15 de junho de 2020.

RENZETTI, Rogério. Série, Provas \& Concursos Direito do Trabalho - teoria e questões práticas. $5^{\mathrm{a}}$ edição. São Paulo: Editora Forense, 2018.

SILVA, Luiz Augusto Triani Gonzaga da. Relações trabalhistas sob os efeitos do coronavírus. 25 de março de 2020. Disponível em: <https://www.migalhas.com.br/depeso/322687/relacoestrabalhistas-sob-os-efeitos-do-coronavirus>. Acesso em: 15 de junho de 2020 .

SUPREMO TRIBUNAL FEDERAL. ADI 6363. Relator Ministro Ricardo Lewandowski. Disponível em:<http://www.stf.jus.br/arquivo/cms/noticiaNoticiaStf/ anexo/ADI6363.pdf>. Acesso em: 05 de julho de 2020.

TEMÓTEO, Antônio. INSS pagará por primeiros 15 dias de afastamento de empregado com covid-19. UOL, Brasília, 19 de março de 2020. Disponível em:<https://economia.uol.com.br/noticias/redacao/2020/0 3/19/inss-pagara-por-primeiros-15-dias-de-afastamentode-empregado-com-covid-19.htm>. Acesso em: 18 de junho de 2020 . 